\title{
Therapeutic effect of mitoxantrone combined with methylprednisolone in multiple sclerosis: a randomised multicentre study of active disease using MRI and clinical criteria
}

Gilles Edan, David Miller, Michel Clanet, Christian Confavreux, Olivier Lyon-Caen, Catherine Lubetzki, Bruno Brochet, Isabelle Berry, Yan Rolland, Jean-Claude Froment, Vincent Dousset, Emmanuelle Cabanis, Marie-Thérèse Iba-Zizen, Jean-Marc Gandon, H M Lai, Ivan Moseley, Olivier Sabouraud

Department of Neurology, Centre Hospitalier Universitaire, Rennes, France

G Edan

Y Rolland

O Sabouraud

Institute of Neurology, The National Hospital Queen Square,

London, UK

D Miller

I Moseley

H M Lai

Department of

Neurology, CHU

Purpan, Toulouse,

France

M Clanet

I Berry

Department of Neurology, Hopital de l'Antiquaille, Lyon, France

J-C Froment

C Confavreux

Department of

Neurology, Groupe

hospitalier Pitié-

Salpétrière, Paris,

France

O Lyon-Caen

C Lubetzki

E Cabanis

M-T Iba-Zizen

Department of

Neurology, CHU,

Bordeaux, France

B Brochet

V Dousset

Biotrial, CRO,

Rennes, France

J-M Gandon

Correspondence to:

Professor Gilles Edan,

Department of Neurology,

CHRU Pontchaillou, Rue

Henri Le Guilloux, 35033

Received 7 May 1996

and in revised form

2nd September 1996

Accepted 20 September 1996

\begin{abstract}
Objective-To evaluate the efficiency of mitoxantrone in multiple sclerosis.

Methods-Forty two patients with confirmed multiple sclerosis, selected as having a very active disease on clinical and MRI criteria were randomised to receive either mitoxantrone ( $20 \mathrm{mg}$ intravenously (IV) monthly) and methylprednisolone ( $1 \mathrm{~g}$ iv monthly) or methylprednisolone alone over six months. In the steroid alone group five patients dropped out due to severe exacerbation.
\end{abstract}

Results-Blinded analysis of MRI data showed significantly more patients with no new enhancing lesions in the mitoxantrone group compared with the steroid alone group, $(90 \% v 31 \%, P<0.001)$. In the mitoxantrone group there was a month by month decrease almost to zero in the number of new enhancing lesions, and in the total number of enhancing lesions, whereas both remained high in the steroid alone group. The differences were significant for both indices at all months from 1-6. Unblinded clinical assessments showed a significant improvement in change in EDSS at months 2-6 in the mitoxantrone group, with a final mean improvement of more than one point $(-1 \cdot 1 v+0.3 ; P<0.001)$. There was a significant reduction in the number of relapses $(7 v 31 ; P<0 \cdot 01)$, and an increase in the number of patients free of exacerbation (14v 7; P< 0.05).

Conclusion-In this selected group of patients with multiple sclerosis with very active disease, mitoxantrone combined with methylprednisolone was effective in improving both clinical and MRI indices of disease activity over a period of six months whereas methylprednisolone alone was not. Further double blinded long term studies are needed to properly evaluate the effect of mitoxantrone on progression in disability.

(F Neurol Neurosurg Psychiatry 1997;62:112-118)

Keywords: multiple sclerosis; magnetic resonance imaging; mitoxantrone; methylprednisolone

Immunological mechanisms have long been thought important in the pathogenesis of multiple sclerosis, and several controlled trials of immunosuppressive therapy have been undertaken. ${ }^{1-7}$ With the possible exception of interferon- $\beta,{ }^{8} 10$ these trials have only shown a modest, if any, beneficial effect on the course of the disease.

Mitoxantrone is an anthracenedione antineoplastic agent that intercalates with $\mathrm{DNA}^{11}$ and exerts a potent immunomodulating effect that suppresses humoral immunity, ${ }^{12}$ reduces $T$ cell numbers, abrogates helper activity, and enhances suppressor function. ${ }^{13}$ It is highly effective in suppressing the development of acute experimental allergic encephalomyelitis $(E A E)^{14}{ }^{15}$ and prevents or delays relapse in a chronic relapsing model of EAE. ${ }^{16}$ Studies by Gonsette and Demanty ${ }^{17}$ and later workers ${ }^{18-22}$ have suggested a possible therapeutic effect of mitoxantrone on multiple sclerosis. We have therefore evaluated the efficacy of mitoxantrone using both clinical and MRI criteria in a group of patients with multiple sclerosis selected as having a very active disease.

\section{Methods}

From October 1992 to October 1994, neurologists from five French University hospitals assigned 42 patients with very active multiple sclerosis to receive mitoxantrone $(20 \mathrm{mg}$ intravenously (iv)/month) and methylprednisolone ( $1 \mathrm{~g}$ iv/month) or methylprednisolone alone ( $1 \mathrm{~g}$ iv/month) by the trial randomisation code for a period of six months.

\section{SELECTION OF PATIENTS}

There was a two step selection. Patients were first selected clinically, then on MRI criteria. The clinical inclusion criteria were diagnosis of clinically definite multiple sclerosis (Poser criteria), age between 18 and 45 years, duration of disease less than 10 years. The clinical criteria for disease activity were either two relapses with sequelae within the previous 12 months or progression of two points on the EDSS scale during that time in those with secondary progressive disease. Relapsing-remitting course was defined as the occurrence of exacerbations followed by complete or partial remission, but without slow progression of disability between the relapses. Secondary progressive course was defined by the occurrence of a slow worsening of the disability lasting 
more than six months, with or without relapses, in patients having had, before the progression phase, a relapsing-remitting course. ${ }^{23}$ Patients with relapsing disease had not had intensive steroid therapy for at least one month at the time of selection, or immunosuppressive agents within the past three months. Patients had to be ambulant (EDSS 6 or less). Patients with concomitant systemic disease, cardiac disease, and mental deficit were excluded. Women of child bearing age were required to have effective birth control.

During a baseline period of two months (month -2 , month -1 , month 0 ), three monthly gadolinium enhanced MRI scans were performed. During this baseline period, and throughout the trial, single iv injections of methylprednisolone (1 $\mathrm{g}$ after each monthly MRI) were given to all patients because it was considered appropriate to offer some active therapy in view of their highly aggressive course. Only patients developing at least one active MRI lesion during the baseline period were randomised. The allocation of the treatment at month 0 was done after inclusion by a central randomisation service by fax.

Eighty five patients fulfilled the clinical inclusion criteria. Forty three were then excluded, 36 who had no new lesions on MRI, three who had borderline abnormalities on echocardiography, three who had other clinical adverse events before entry, and one who had a severe relapse at entry and was too ill to participate. Accordingly, 42 patients were randomised into two groups: 21 to receive mitoxantrone combined with methylprednisolone, 21 to have methylprednisolone alone. Additional courses of steroid (methylprednisolone; $1 \mathrm{~g} /$ day iv for three days) were allowed for relapses.

\section{MRI PROTOCOL}

The MRI imaging protocol (used monthly at each neurological centre) was that proposed by the European Concerted Action guidelines. ${ }^{24}$ Axial $5 \mathrm{~mm}$ thick slices were obtained through the brain with proton density and T2 weighted spin echo (SE) images before contrast, and a $\mathrm{T} 1$ weighted SE sequence after injection of gadolinium DTPA $(0 \cdot 1 \mathrm{mmol} / \mathrm{kg})$.

\section{ASSESSMENT AND FOLLOW UP}

The MRI analysis was conducted at the NMR research unit, Institute of Neurology, London, by two observers who were totally blinded to the patients' clinical status, to randomisation, (treatment schedule), and had no contact at all with the patients throughout the study. The assessments of activity on the gadolinium enhanced and T2 weighted images were performed independently of one another. The size of new T2 lesions was classified as small if the maximum diameter was less than $5 \mathrm{~mm}$, medium if the maximum diameter was 5-10 $\mathrm{mm}$, and large where the maximum diameter was more than $10 \mathrm{~mm}$.

Clinical assessments (including EDSS and recording of relapses) were carried out in each centre every month during the baseline period and until completion of the trial. The relapses were documented by neurological examination, marked by the occurrence of symptom(s) of neurological dysfunction lasting more than 48 hours and preceded by stability or improvement for at least 30 days. These assessments were blind to MRI data but, for practical reasons, were not blind to treatment group.

Haematological and liver function tests and ECG were carried out monthly. Echocardiography was performed at entry and exit from the trial. The trial had full ethical approval.

\section{MAJOR OUTCOME CRITERIA AND STATISTICAL} ANALYSIS

The primary outcome criterion was the proportion of patients developing or not developing new enhanced lesions on serial gadolinium enhanced scans performed each month. The secondary criteria were the mean number of new enhanced lesions per month per patient, the number of new T2 lesions between month 0 and exit, and the monthly clinical outcome as assessed by EDSS and number of exacerbations.

Clinical and MRI differences between the two groups were tested for significance using non-parametric methods (Wilcoxon test), and differences between proportions with the $\chi^{2}$ test. The $P$ values were based on a two tailed test.

\section{Results}

There was no difference between the two patient groups in age, sex ratio, age at onset, duration of the disease, and total number of relapses since onset of multiple sclerosis (table 1). Six patients in the non-mitoxantrone group and four patients in the mitoxantrone group had secondary progressive multiple sclerosis whereas the remainder had relapsing-remitting disease. The EDSS at month -2 indicated moderate to severe disability in both groups (mean EDSS $4 \cdot 7$, and 4.4 in the non-mitoxantrone and mitoxantrone groups respectively), indicating relatively severe handicap with respect to disease duration. There were an average of 2.4 and 3.1 relapses within the 12 previous months in the non-mitoxantrone and mitoxantrone groups respectively.

Table 1 Characteristics of patients

\begin{tabular}{lll}
\hline Variable & $\begin{array}{l}M P \\
(n=21)\end{array}$ & $\begin{array}{c}M P+M X \\
(n=21)\end{array}$ \\
\hline Age (y) & $32 \cdot 2(8 \cdot 1)$ & $31 \cdot 4(8 \cdot 3)$ \\
Sex ratio (M/F) & $10 / 11$ & $6 / 15$ \\
RRMS/SPMS ratio & $15 / 6$ & $17 / 4$ \\
Age at MS onset (y) & $26 \cdot 6(6 \cdot 5)$ & $25 \cdot 1(7 \cdot 0)$ \\
Duration of MS $(\mathrm{y})$ & $5 \cdot 7(4 \cdot 0)$ & $6 \cdot 9(3 \cdot 6)$ \\
EDSS at month - & $4 \cdot 7(1 \cdot 5)$ & $4 \cdot 4(1 \cdot 8)$ \\
No of exacerbations since MS & $6 \cdot 1(3 \cdot 7)$ & $7 \cdot 4(4 \cdot 5)$ \\
$\quad$ onset & $6 \cdot 1(3 \cdot 5)$ & $3 \cdot 1(1 \cdot 8)$ \\
\hline $\begin{array}{l}\text { No of exacerbations in the } 12 \\
\text { months months preceding entry }\end{array}$ & $2 \cdot 4(1 \cdot 7)$ & \\
\hline
\end{tabular}

Data are means (SD). There were no significant differences between the groups. MP = treated with methylprednisolone along; $\mathrm{MP}+\mathrm{MX}=$ treated with methylprednisolone + mitoxantrone; $\mathrm{M} / \mathrm{F}=$ male/female; EDSS = expanded disability antrone; $\mathrm{M} / \mathrm{F}=\mathrm{male} / \mathrm{female} ; \mathrm{EDSS}=$ expanded disability status scale; RRMS = relapsing-remitting multipl 
Table 2 Description of the five patents who dropped out*

\begin{tabular}{llllll}
\hline $\begin{array}{l}\text { Time at drop out } \\
\text { (months) }\end{array}$ & $\begin{array}{l}\text { EDSS at } \\
\text { month }-2\end{array}$ & $\begin{array}{l}\text { EDSS at } \\
\text { drop out }\end{array}$ & $\begin{array}{l}\text { No of } \\
\text { relapses from } \\
\text { month -2 }\end{array}$ & $\begin{array}{l}\text { No of new } \\
\text { enhancing } \\
\text { lesions from } \\
\text { month }-2\end{array}$ & $\begin{array}{l}\text { No of scans } \\
\text { with new } \\
\text { enhancing } \\
\text { lesions }\end{array}$ \\
\hline 4 & $5 \cdot 5$ & 6.5 & 4 & 35 & $6 / 7$ \\
4 & 4.5 & $5 \cdot 0$ & 3 & 14 & $7 / 7$ \\
4 & $6 \cdot 0$ & 8.5 & 3 & 98 & $7 / 7$ \\
3 & 6.0 & 7.5 & 2 & 51 & $6 / 6$ \\
5 & 4.5 & 8.0 & 3 & 99 & $7 / 7$ \\
\hline
\end{tabular}

^All five patients dropped out because of apparent lack of effectiveness and were in the methylprednisolone group. EDSS = expanded disability status scale.

During the baseline period, 42 patients who satisfied both clinical and MRI criteria for randomisation had 21 relapses, giving an annual relapse rate of three, similar to their relapse rate during the preceding 12 months. By contrast, in the 36 patients who satisfied the clinical criteria for randomisation, but were excluded for lack of new MRI lesions, there were only four relapses during the baseline period, giving an annual rate of 0.7 . This difference was significant $(P<0.01)$. During treatment, five patients dropped out at months 3,4 , or 5 , because of pronounced deterioration. All were in the steroid only group, and had highly active disease both on clinical and MRI criteria (table 2). The patients were withdrawn to receive immunosuppressive treatment.

PRIMARY END POINT: PERCENTAGE OF PATIENTS WITHOUT NEW ENHANCING LESIONS At entry (month 0), the percentage of patients without new enhancing lesions was $4 \cdot 8 \%$ and $10 \%$ in the non-mitoxantrone and mitoxantrone groups respectively. During the treatment period, in the mitoxantrone group, starting from month 2 onward, this percentage increased and reached $90.5 \%$ by month six (figure). In the non-mitoxantrone group, there was a much smaller increase to $31 \cdot 3 \%$. This difference was highly significant. Differences at months 2,3 , and 5 were also significant, and in favour of the mitoxantrone group.

SECONDARY END POINTS

During the baseline period, the mean monthly

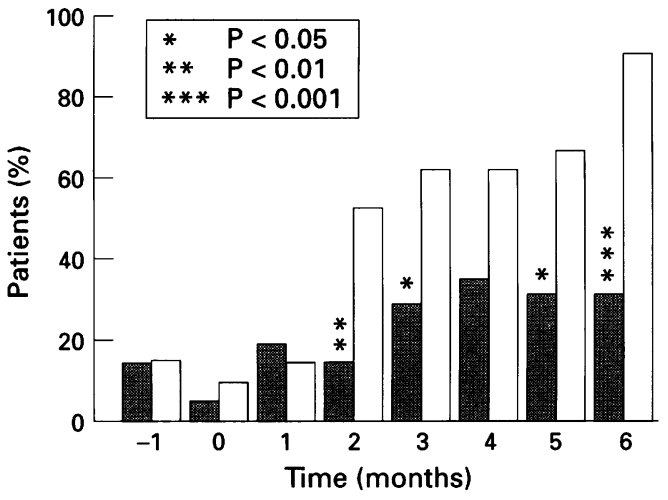

Percentage of patients without new active lesions (MRI) each month after monthly iv injection of $1 \mathrm{~g}$ methylprednisolone (grey bars) or $1 \mathrm{~g}$ methylprednisolone $+20 \mathrm{mg}$ mitoxantrone (open bars). $M-1=$ one month before inclusion (M0); M1 to M6 = one to six month after inclusion. ${ }^{\star} P<0.05 ; * \star P<0.01 ; * \star * P<0.001$

number of new enhancing MRI lesions varied between 4.6 and $9 \cdot 1$. During the treatment period, the mean monthly number of new enhancing lesions varied between 2.9 and 13.2 in the non-mitoxantrone group and between 0.1 and 2.6 in the mitoxantrone group. The number was less in the mitoxantrone group in all months, and the differences were significant from months 1 to 6 (table 3). The comparison of the monthly mean number of enhancing lesions (new lesions and persisting enhancing lesions) also showed significant differences in months 1 to 6 (table 3).

New and total (total $=$ new and persisting enhancing lesions) contrast enhanced lesion frequency during the baseline period compared with the treatment period were significantly different in the mitoxantrone group whereas there were no statistical differences between these two periods in the non-mitoxantrone group (table 4).

We compared the T2 images at exit (month 6 for 36 patients, month 4 for four patients) with those at month 0 . The mean number of new moderate, large, and total T2 lesions was significantly lower in the mitoxantrone group (table 5).

Table 3 MRI: number of new and total enhancing lesions

\begin{tabular}{|c|c|c|c|c|c|c|c|c|c|}
\hline & \multicolumn{9}{|l|}{ Month $\dagger$} \\
\hline & -2 & -1 & 0 & 1 & 2 & 3 & 4 & 5 & 6 \\
\hline \multicolumn{10}{|c|}{$\begin{array}{l}\text { Number of new enhancing lesions: } \\
\text { MP }\end{array}$} \\
\hline $\begin{array}{l}\mathrm{n} \\
\text { Mean (SD) } \\
\text { Median (range) }\end{array}$ & $\begin{array}{l}- \\
-\end{array}$ & $\begin{array}{l}20^{\star} \\
9 \cdot 1(17.9) \\
2 \cdot 5(0-78)\end{array}$ & $\begin{array}{l}21 \\
5 \cdot 1(5 \cdot 7) \\
3(0-23)\end{array}$ & $\begin{array}{l}21 \\
12 \cdot 3(28 \cdot 8) \\
5(0-135)\end{array}$ & $\begin{array}{l}21 \\
5.7(7.5) \\
2(0-26)\end{array}$ & $\begin{array}{l}21 \\
9 \cdot 2(25 \cdot 8) \\
2(0-120)\end{array}$ & $\begin{array}{l}20 \ddagger \\
8 \cdot 9(16 \cdot 7) \\
1(0-65)\end{array}$ & $\begin{array}{l}16^{\star} \ddagger \\
3 \cdot 8(5 \cdot 3) \\
1(0-17)\end{array}$ & $\begin{array}{l}16 \ddagger \\
2 \cdot 9(3 \cdot 2) \\
2(0-11)\end{array}$ \\
\hline $\begin{array}{l}M P+M X \\
\mathrm{n} \\
\text { Mean (SD) } \\
\text { Median (range) } \\
\text { P value (W) }\end{array}$ & $\begin{array}{l}\bar{z} \\
\bar{z}\end{array}$ & $\begin{array}{l}20^{\star} \\
6 \cdot 8(8 \cdot 3) \\
3(0-32) \\
\text { NS }\end{array}$ & $\begin{array}{l}20^{\star} \\
4 \cdot 6(4 \cdot 6) \\
3(0-18) \\
\text { NS }\end{array}$ & $\begin{array}{l}21 \\
\quad 1.9(1.4) \\
2(0-5) \\
<0.05\end{array}$ & $\begin{array}{l}21 \\
2 \cdot 6(5 \cdot 7) \\
0(0-21) \\
<0.05\end{array}$ & $\begin{array}{l}21 \\
1 \cdot 1(2 \cdot 7) \\
0(0-12) \\
<0.05\end{array}$ & $\begin{array}{l}21 \\
0.9(1.6) \\
0(0-7) \\
<0.05\end{array}$ & $\begin{array}{l}21 \\
0.6(1.5) \\
0(0-7) \\
<0.01\end{array}$ & $\begin{array}{l}21 \\
0.1(0.5) \\
0(0-2) \\
<0.001\end{array}$ \\
\hline \multicolumn{10}{|c|}{$\begin{array}{l}\text { Total number of enhancing lesions: } \rrbracket \\
\text { MP }\end{array}$} \\
\hline $\begin{array}{l}\mathrm{n} \\
\text { Mean (SD) } \\
\text { Median (range) }\end{array}$ & $\begin{array}{l}20^{\star} \\
8 \cdot 2(8 \cdot 6) \\
6(0-32)\end{array}$ & $\begin{array}{l}21 \\
10 \cdot 2(18 \cdot 6) \\
4(0-81)\end{array}$ & $\begin{array}{l}21 \\
6 \cdot 3(6 \cdot 7) \\
4(0-24)\end{array}$ & $\begin{array}{l}21 \\
13 \cdot 1(28 \cdot 6) \\
\quad 6(0-135)\end{array}$ & $\begin{array}{l}21 \\
6 \cdot 5(7 \cdot 8) \\
3(0-26)\end{array}$ & $\begin{array}{l}21 \\
9 \cdot 8(25 \cdot 7) \\
3(0-120)\end{array}$ & $\begin{array}{l}20 \ddagger \\
9 \cdot 7(17 \cdot 3) \\
2(0-68)\end{array}$ & $\begin{array}{l}16^{\star} \ddagger \\
4 \cdot 2(5 \cdot 7) \\
2(0-19)\end{array}$ & $\begin{array}{l}16 \ddagger \\
3 \cdot 1(3 \cdot 2) \\
2 \cdot 5(0-11)\end{array}$ \\
\hline $\begin{array}{l}\mathrm{MP}+\mathrm{MX} \\
\quad \mathrm{n} \\
\text { Mean (SD) } \\
\quad \text { Median (range) } \\
\text { P value (W) }\end{array}$ & $\begin{array}{l}20^{\star} \\
7 \cdot 1(8 \cdot 3) \\
5(0-30) \\
\text { NS }\end{array}$ & $\begin{array}{l}20^{\star} \\
9 \cdot 5(12 \cdot 2) \\
3 \cdot 5(0-48) \\
\text { NS }\end{array}$ & $\begin{array}{l}21 \\
5 \cdot 7(6 \cdot 3) \\
3(0-22) \\
\text { NS }\end{array}$ & $\begin{array}{l}21 \\
3 \cdot 3(4 \cdot 0) \\
2(0-18) \\
<0 \cdot 05\end{array}$ & $\begin{array}{l}21 \\
3 \cdot 6(7 \cdot 6) \\
1(0-31) \\
<0 \cdot 05\end{array}$ & $\begin{array}{l}21 \\
2 \cdot 5(6 \cdot 6) \\
0(0-28) \\
<0 \cdot 01\end{array}$ & $\begin{array}{l}21 \\
2 \cdot 3(6 \cdot 6) \\
0(0-30) \\
<0 \cdot 05\end{array}$ & $\begin{array}{l}21 \\
1.9(6.0) \\
0(0-27) \\
<0.01\end{array}$ & $\begin{array}{l}21 \\
\quad 1 \cdot 4(5 \cdot 7) \\
0(0-26) \\
<0 \cdot 001\end{array}$ \\
\hline
\end{tabular}

MP = Treated by methylprednisolone alone; $M P+M X=$ treated by methylprednisolone + mitoxantrone. $n=$ patient numbers; ${ }^{\star}$ One $M R I$ was uninterpretable;

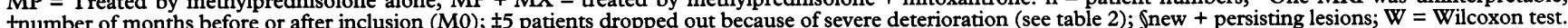


Table 4 Number of new and total contrast enhanced lesions during two months of pretreatment and six months of treatment

\begin{tabular}{|c|c|c|c|}
\hline Variable & $\begin{array}{l}\text { Baseline period } \\
(M-2-M O)\end{array}$ & $\begin{array}{l}\text { Treatment period } \\
(M 1-M 6)\end{array}$ & $P$ value $(W)$ \\
\hline \multicolumn{4}{|c|}{$\begin{array}{l}\text { Number of new enhancing lesions per scan: } \\
\text { MP }\end{array}$} \\
\hline $\begin{array}{l}\text { Mean (SD) } \\
\text { Median (range) }\end{array}$ & $\begin{array}{l}7 \cdot 0(13 \cdot 0) \\
3(0-78)\end{array}$ & $\begin{array}{l}7 \cdot 5(18 \cdot 3) \\
2(0-135)\end{array}$ & NS \\
\hline $\mathrm{MP}+\mathrm{MX}$ & & & \\
\hline $\begin{array}{l}\text { Mean (SD) } \\
\text { Median (range) }\end{array}$ & $\begin{array}{l}5 \cdot 6(6 \cdot 7) \\
3(0-32)\end{array}$ & $\begin{array}{l}1 \cdot 2(2 \cdot 9) \\
0(0-21)\end{array}$ & $<0.001$ \\
\hline \multicolumn{4}{|c|}{$\begin{array}{l}\text { Total number of enhancing lesions per scan: } \\
\text { MP }\end{array}$} \\
\hline $\begin{array}{l}\text { Mean (SD) } \\
\text { Median (range) }\end{array}$ & $\begin{array}{l}8 \cdot 3(12 \cdot 5) \\
5(0-81)\end{array}$ & $\begin{array}{l}8 \cdot 1(18 \cdot 4) \\
3(0-135)\end{array}$ & \multirow[t]{2}{*}{ NS } \\
\hline$M P+M X$ & & & \\
\hline $\begin{array}{l}\text { Mean (SD) } \\
\text { Median (range) }\end{array}$ & $\begin{array}{l}7 \cdot 5(9 \cdot 2) \\
4(0-48)\end{array}$ & $\begin{array}{l}2 \cdot 5(6 \cdot 1) \\
0(0-31)\end{array}$ & $<0.001$ \\
\hline
\end{tabular}

MP = Treated by methylprednisolone alone; $\mathrm{MP}+\mathrm{MX}=$ treated by methylprednisolone + mitoxantrone; $(M-2-M 0)=$ two month period before inclusion; $(M 1-M 6)=$ six month period before inclusion; $(M 1-M 6)=$ six month treatment period after inclusion; $\mathbb{W}=$ Wilcoxon test.

Table 5 Number of new lesions on the T2 weighted scans between inclusion (month 0 ) and end of study (month 6)

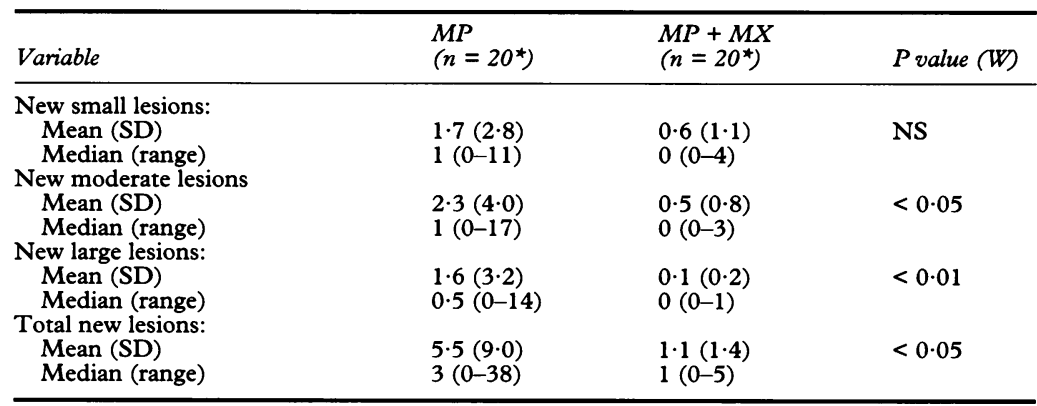

One MRI was not interpretable; $\mathrm{MP}=$ treated by methylprednisolone alone; $\mathrm{MP}+\mathrm{MX}=$ treated by methylprednisolone + mitoxantrone; $W=$ Wilcoxon test; small: $<5$ mm; moderate: 5 to $10 \mathrm{~mm}$; large: $>10 \mathrm{~mm}$.
Table 7 Number and percentage of patients with one point confirmed variation * ${ }^{*}$ EDSS between $M O$ (inclusion) and the end of the study

$\left.\begin{array}{lrrr}\hline \text { Variable } & M P & M P+M X & \text { P value }\left(\chi^{2}\right) \\ \hline \text { Deterioration } & 6(28 \cdot 6) & 1(4 \cdot 8) \\ \text { Stable } & 12(57 \cdot 1) & 8(38 \cdot 1) \\ \text { Improvement } & 3(14 \cdot 3) & 12(57 \cdot 1)\end{array}\right\}<0.01$

$M P=$ Treated by methylprednisolone alone; $M P+M X=$ treated by methylprednisolone + mitoxantrone; EDSS = treated by methylprednisolone + mitoxantrone; EDSS $=$ from 6.5 to 7.0 on EDSS were considered equivalent to one point change. ${ }^{\star} T$ The one point variation was measured for two point change. ${ }^{\star}$ The one point variation
months running, at the end of the study.

7) between month 0 and the end of the study was clearly different, showing that in the mitoxantrone group 12 out of 21 patients improved one point or more on the EDSS and only one deteriorated. By contrast, in the non-mitoxantrone group, six deteriorated and only three improved.

\section{EXACERBATIONS (TABLE 8)}

During the two month baseline period, the mitoxantrone and non-mitoxantrone groups had 12 and nine exacerbations respectively, giving calculated annual rates of $3 \cdot 4$ and $2 \cdot 6$, similar to the 12 preceding months. However, during the treatment period, there were fewer relapses in the mitoxantrone group ( $7 v 2 \quad 31$ relapses). This effect was even more pronounced during the last four months of the treatment ( $1 v 18$ relapses). Only five additional high dose steroid courses for relapses were given in the mitoxantrone group compared with 19 for the non-mitoxantrone group. During the treatment period, the number of patients free of exacerbations was 14 out of 21 in the mitoxantrone group and 7 out of 21 in the nonmitoxantrone group.

\section{ADVERSE EVENTS}

Several adverse events were recorded, more in the mitoxantrone group than in the non-mitoxantrone group. There was no evidence of serious side effects. In particular, no cardiotoxicity was detected. Six patients in the non-mitoxantrone group and 18 in the mitoxantrone group had at least one adverse event (table 9). Alopecia was only minor and transient for seven patients. Eight out of 15 women developed

Table 6 EDSS during two months of pretreatment and six months of treatment

\begin{tabular}{|c|c|c|c|c|c|c|c|c|c|}
\hline & \multicolumn{9}{|l|}{ Month† } \\
\hline & -2 & -1 & 0 & 1 & 2 & 3 & 4 & 5 & 6 \\
\hline \multicolumn{10}{|l|}{$\begin{array}{c}\text { EDSS: } \\
\text { MP }\end{array}$} \\
\hline $\begin{array}{l}\mathbf{n} \\
\text { Mean (SD) } \\
M P+M X\end{array}$ & $\stackrel{21}{4 \cdot 7}(1 \cdot 5)$ & $\stackrel{21}{4 \cdot 5(2 \cdot 0)}$ & $\stackrel{21}{4 \cdot 6(1 \cdot 7)}$ & $\stackrel{21}{4 \cdot 9}(2 \cdot 1)$ & $\begin{array}{l}21 \\
4.9 \\
(1 \cdot 8)\end{array}$ & 21 & $\begin{array}{l}20 \ddagger \\
5 \cdot 1(1 \cdot 8)\end{array}$ & $\begin{array}{l}17 \ddagger \\
4 \cdot 5(2 \cdot 1)\end{array}$ & $\begin{array}{l}16 \ddagger \\
4 \cdot 3(2 \cdot 1)\end{array}$ \\
\hline $\begin{array}{c}\mathbf{n} \\
\text { Mean (SD) } \\
\text { P value (W) } \\
\text { Change in EDSSt: } \\
\mathbf{M P}\end{array}$ & $\begin{array}{l}21 \\
\stackrel{4}{4} 4(1 \cdot 9) \\
\text { NS }\end{array}$ & $\begin{array}{l}21 \\
4 \cdot 5(1 \cdot 7) \\
\text { NS }\end{array}$ & $\begin{array}{l}21 \\
4.5(1 \cdot 6) \\
\text { NS }\end{array}$ & $\begin{array}{l}12 \\
4 \cdot 2(1 \cdot 6) \\
\text { NS }\end{array}$ & $\begin{array}{l}21 \\
\text { NS }\end{array}$ & $\begin{array}{l}21 \\
3.9(1.8) \\
\text { NS }\end{array}$ & $\begin{array}{l}21 \\
3.6(2 \cdot 0) \\
<0.05\end{array}$ & $\begin{array}{l}21 \\
3 \cdot 4(1 \cdot 9) \\
\text { NS }\end{array}$ & $\begin{array}{l}21 \\
3 \cdot 4(1 \cdot 9) \\
\text { NS }\end{array}$ \\
\hline 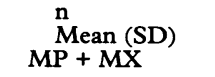 & - & - & - & $\stackrel{21}{0 \cdot 2(1 \cdot 3)}$ & $\stackrel{21}{0 \cdot 3}(1 \cdot 2)$ & $\stackrel{21}{0 \cdot 3(1 \cdot 1)}$ & $\begin{array}{l}20 \ddagger \\
0 \cdot 6(1 \cdot 3)\end{array}$ & $\begin{array}{l}17 \ddagger \\
0 \cdot 1(1 \cdot 2)\end{array}$ & $\begin{array}{l}16 \neq \\
-0 \cdot 1(1 \cdot 1)\end{array}$ \\
\hline $\begin{array}{l}\text { Mean (SD) } \\
\text { P value (W) }\end{array}$ & - & - & - & $\begin{array}{l}21 \\
-0 \cdot 3(0 \cdot 7) \\
\text { NS }\end{array}$ & $\begin{array}{l}21 \\
-0.4(0.8) \\
<0.05\end{array}$ & $\begin{array}{l}21 \\
-0.6(0 \cdot 8) \\
<0.01\end{array}$ & $\begin{array}{l}21 \\
-0.9(0.9) \\
<0.001\end{array}$ & $\begin{array}{l}21 \\
-1 \cdot 1(1 \cdot 0) \\
<0.01\end{array}$ & $\begin{array}{l}21 \\
-1 \cdot 1(1 \cdot 1) \\
<0.05\end{array}$ \\
\hline
\end{tabular}

$\mathrm{MP}=$ Treated by methylprednisolone alone; $\mathrm{MP}+\mathrm{MX}=$ treated by methylprednisolone + mitoxantrone; EDSS = Expanded disability status scale; $\mathrm{n}=$ patient numbers. ${ }^{\star}$ number of months before or after inclusion $(\mathrm{m} 0)$; + changes in EDSS referred to M0 (inclusion); ‡five patients dropped out (see table 2); W = Wilcoxon test. 
Table 8 Relapses and patients free of exacerbations during two months of pretreatment and six months of treatment

\begin{tabular}{|c|c|c|c|}
\hline Variable & $M P$ & $M P+M X$ & $P$ value $\left(\chi^{2}\right.$ or $\left.W\right)$ \\
\hline \multicolumn{4}{|l|}{ Relapses: } \\
\hline \multicolumn{4}{|l|}{ Baseline period: } \\
\hline Number of relapses & 9 & 12 & \\
\hline Annual rate/patient & $2 \cdot 6$ & $3 \cdot 4$ & NS \\
\hline Additional steroid courses (iv high doses) & 5 & & \\
\hline \multicolumn{4}{|l|}{ During treatment period: } \\
\hline M0-M6 & & & \\
\hline Number of relapses & 31 & 7 & \\
\hline Annual rate/patient & $3 \cdot 0$ & 0.7 & $<0.01$ \\
\hline Additional steriod courses (iv high doses) & 19 & 5 & \\
\hline \multicolumn{4}{|l|}{$\mathrm{MO}-\mathrm{M} 2$} \\
\hline Number of relapses & 13 & 6 & \\
\hline Annual rate/patient & $3 \cdot 7$ & $1 \cdot 7$ & \\
\hline \multicolumn{4}{|l|}{ M3-M6 } \\
\hline Number of relapses & 18 & 1 & \\
\hline Annual rate/patient & $2 \cdot 6$ & $0 \cdot 1$ & \\
\hline \multicolumn{4}{|l|}{ Number of patients free of exacerbations: } \\
\hline Baseline period: & 13 & 10 & NS \\
\hline \multicolumn{4}{|l|}{ During treatment period: } \\
\hline M0-M6 & 7 & 14 & $<0.05$ \\
\hline M0-M2 & 11 & 15 & \\
\hline M3-M6 & 9 & 20 & \\
\hline
\end{tabular}

$\mathrm{MP}=$ treated by methylprednisolone alone; $\mathrm{MP}+\mathrm{MX}=$ treated by methylprednisolone + mitoxantrone; $M 0=$ inclusion; $M 2=$ two months after inclusion etc. The separation between M0-M2 and M3-M6 illustrate the difference between the first and the second part of the trial; $\mathrm{W}=\mathrm{W}$ ilcoxon test. of frequent serial MRI to obtain an initial assessment of the efficacy of new therapies on disease activity in multiple sclerosis. ${ }^{24-28}$ Such an approach in early relapsing-remitting and secondary progressive multiple sclerosis can show treatment effects within a matter of months in only a few patients, because serial MRI shows much more disease activity than is clinically apparent. We therefore used monthly gadolinium enhanced MRI as the primary outcome measure in this short term study of the efficacy of mitoxantrone. The study showed a pronounced and highly significant reduction in the frequency of new enhancing lesions in the group treated with mitoxantrone and methylprednisolone compared with the group treated with methylprednisolone alone. It is notable that we saw a much higher rate of enhancing lesions than $\mathrm{T} 2$ lesions. This can partly be related to the fact that there was a greater frequency of sampling (monthly $v$ six monthly), but even when gadolinium enhanced and T2 weighted scans are analysed at the same (monthly) intervals, it has been shown that there is an appreciably higher level of activity detecting using enhancement. ${ }^{29}$ The explanations for this increase are many and include re-enhancement of old lesions, and a generally greater conspicuity of small areas of new activity on enhanced images.

Clinical trial methodology normally demands double blinding. In the present study, although the allocation of treatment was performed using an unbiased randomisation service, neither the patients nor the clinical investigators were blinded during the study. Blinding of patients was not possible in this trial, as obvious side effects of mitoxantrone were experienced in almost all cases. Blinding of the physician was made difficult by the fall in white cell count that always accompanies mitoxantrone treatment. Blind clinical observers might have been appointed, but this could not be done for economic reasons. The clinical efficacy suggested in this study must therefore be regarded with caution as it was acquired unblinded.

Looking at the non-mitoxantrone group gives us the opportunity to assess the effect of methylprednisolone alone. These patients had regular monthly methylprednisolone injections in addition to a three day course of methylprednisolone for relapses as needed. The regular monthly treatment was done because we thought that some treatment should be offered to patients with such aggressive disease. The efficacy of methylprednisolone alone was clearly poor. The non-mitoxantrone group required 19 additional steroid courses for severe exacerbations. Despite the regular, but intermittent methylprednisolone treatment, the number of patients with new enhancing MRI lesions decreased only slightly and nonsignificantly. This slight improvement may be a natural history phenomenon (regression to the mean) and not a steroid effect. The effect of a three day course of iv methylprednisolone on enhancing lesions probably lasts for less than one week. ${ }^{30}$ This marginal improvement on 
MRI was, moreover, not associated with clinical benefit as five patients in this group dropped out of the trial because of pronounced deterioration, the relapse rate did not decrease, and the EDSS did not improve.

Open pilot studies of mitoxantrone treatment have suggested some therapeutic effect. ${ }^{17-20}$ A recent controlled study ${ }^{21}$ showed a reduction in relapses, but no significant difference in the EDSS scale or in the development of active MRI lesions. This study was of 13 patients, and the patient group had less active disease (a baseline relapse rate of about half) than in the present study. MRI criteria were not used in patient selection, and evaluations were carried out less often. The inclusion criteria used in the present study were specifically aimed at selecting informative patients, and the number studied was sufficient to show meaningful changes. It is likely that this accounts for the fact that we have found a therapeutic effect on MRI in our study.

Mitoxantrone has been widely used as an anticancer drug for more than 10 years. ${ }^{31} 32$ The dose used in oncology is much higher than in multiple sclerosis studies and the main risk, that of cardiotoxicity, seemed to be low at the doses used in the present study (about $70 \mathrm{mg} / \mathrm{m}^{2}$ ). No cases were seen in the present study despite very careful cardiac monitoring, confirming the results of De Castro et al, ${ }^{22}$ and patients were excluded if there were clinical, ECG, or echocardiographic features of cardiac abnormalities. However, although the dose used in this study seemed safe, we cannot dismiss the possibility that subclinical, permanent, and minor cardiac injury induced by the drug could later become clinically symptomatic as patients age and develop the common forms of heart disease. There are three reasons why the results of the present trial do not allow us to draw conclusions as to the long term clinical efficacy of mitoxantrone on the course of multiple sclerosis:

(1) The relation between short term gadolinium enhancement and long term disability is uncertain; preliminary experience suggests that a relationship exists ${ }^{33}$ but confirmation from larger studies is needed.

(2) The apparent short term clinical benefits we saw were unblinded observations and are therefore not wholly reliable.

(3) We cannot exclude the possibility that part of the benefit we saw in the mitoxantrone group came from the addition of methylprednisolone to the treatment regime.

None the less, it was clear in this selective group of patients with multiple sclerosis with very active disease that the combination of mitoxantrone and methylprednisolone greatly improved objective and blinded MRI indices of disease activity over six months, whereas methylprednisolone alone did not. The strong and rapid reduction in the inflammatory process suggests a potential role for mitoxantrone as rescue therapy or as an induction for other long term disease modifying therapies in very active cases of multiple sclerosis. Its effect on the long term clinical course can only be determined by longer term trials.
We thank Geneviève Morel, Irène Brunet Assistante de Recherche Clinique, Isabelle Cimarosti, statisticienne BIOTRIAL, Frank Landgraff, Patricia Cortinovis-Tourniaire, Philippe Petiot, Isabelle Payen, Thibault Moreau, Annie Filleuil, Roderick Duncan, RE Gonsette, Sean Morrissey, and Alan Thompson and Joel Oger.

1 British and Dutch Multiple Sclerosis Azathioprine Trial Group. Double-masked trial of azathioprine in multiple sclerosis. Lancet 1988;ii: 179-83.

2 Goodkin DE, Bailly RC, Teetzen ML, Hertsgaard D, Beatty WW. The efficacy of azathioprine in relapsing remitting multiple sclerosis. Neurology 1991;41:20-5.

3 Kappos L, Patzold U, Dommash D, Poser S, Haas J, Krauseneck $\mathrm{P}$, et al. Cyclosporine versus aziathioprine in long-term treatment of multiple sclerosis-Results of the German multicenter study. Ann Neurol 1988;23:56-63.

4 The multiple Sclerosis Study Group. The efficacy and toxicity of cyclosporine $\mathrm{A}$ in chronic progressive multiple sclerosis: a randomized, double-blinded, placebo-controlled clinical trial. Ann Neurol 1990;27:591-605.

5 The Canadian cooperative trial of cyclophosphamide and plasma exchange in progressive multiple sclerosis. The plasma exchange in progressive multiple sclerosis. The cooperative multipl

6 Weiner HL, Mackin GA, Orav EJ, Hafler DA, Dawson DM, Lapierre Y, et al and the Northeast Cooperative Multiple Sclerosis Treatment Group. Intermittent cyclophosphamide pulse therapy in progressive multiple sclerosis. Neurology 1993;43:910-8.

7 Goodkin DE, Rudick RA, Medendorp SV, Daughtry MM, Scwetz KM, Fischer J, Van Dyke C. Low dose ora methotrexate reduces the rate of progression in chronic progressive multiple sclerosis. Ann Neurol 1995;37: 30-40.

8 The IFNB Multiple Sclerosis Study Group. Interferon beta-1b is effective in relapsing-remitting multiple sclerobeta-1b is effective in relapsing-remitting multiple sclero-
sis. I. Clinical results of a multicenter, randomized, dousis. I. Clinical results of a multicenter, randomized, dou-
ble-blind, placebo-controlled trial. Neurology 1993;43: 655-61.

9 Paty DW, Li DKB; the UBC MS/MRI Study Group; and the IFNB Multiple Sclerosis Study. Interferon beta-1b is effective in relapsing-remitting multiple sclerosis. II MRI analysis results of a multicenter, randomized, doubleblind, placebo-controlled trial. Neurology 1993;43:662-7.

10 Jacobs LD and the Multiple Sclerosis Collaborative Research Group (MSCRG). Intramuscular interferon beta-1 a for disease progression in relapsing multiple sclerosis. Ann Neurol 1996;39:285-94.

11 Rosenberg LS, Carvlin MJ, Krugh TR. The antitumor agent mitoxantrone binds cooperatively to DNA: evidence for heterogeneity in DNA conformation. Biochemistry 1986;25:1002-8.

12 Fidler JM, Dejoy SQ, Gibbons JJ. Selective immunomodulation by the antineoplastic agent mitoxantrone. I.
Suppression of B lymphocyte function. I Immunol Suppression of

13 Fidler JM, Dejoy SQ, Smith FR, Gibbons J. Selective immunomodulation by the antineoplastic agent mitoxantrone. II. Non specific adherent suppressor cells derived from mitoxantrone-treated mice. $\mathcal{f}$ Immunol 1986;136:2747-54.

14 Ridge SC, Sloboda AE, Reynolds RA, Levine S, Oronsky AL, Kerwar SS. Suppression of experimental allergic encephalomyelitis by mitoxantrone. Clin Immunol Immunopathol 1985;35:35-42.

15 Levine S, Saltzman A. Regional suppression, therapy after onset and prevention of relapses in experimental allergic onset and prevention of relapses in experimental allergic
encephalomyelitis by mitoxantrone. $f$ Neuroimmunol encephalomyelitis

16 Lublin FD, Lavasa M, Viti C, Knobler RL. Suppression of acute and relapsing experimental allergic encephalomyelitis with mitoxantrone. Clin Immunol Immunopathol 1987;45:122-8.

17 Gonsette RE, Demonty L. Immunosuppression with mitoxantrone in multiple sclerosis: a pilot study for 2 years in 22 patients [abstract]. Neurology 1990;40(suppl 1):261.

18 Kappos L, Gold R, Künstler E, Rohrbach E, Reinhard H, Detlef S, Hofmann E. Mitoxantrone in the treatment of rapidly progressive multiple sclerosis: a pilot study with serial gadolinium-enhanced MRI [abstract]. Neurology 1990;40(suppl 1):261.

19 Mauch E, Kornhuber MH, Krapf H, Fetzer U, Laufen H. Treatment of multiple sclerosis with mitoxantrone. Treatment of multiple sclerosis with mitoxantrone.
European Archives of Psychiatry and clinical Neuroscience. European Archives

20 Noseworthy JH, Hopkins MB, Vandervoot MK, Karlik SJ, Lee DH, Penman M, et al. An open-trial evaluation of mitoxantrone in the treatment of progressive MS Neurology 1993;43:1401-6.

21 Bastianello S, Pozzilli C, D'Andrea F, Millefiorini E, Trojano $M$, Morino $S$, et al. A controlled trial of mitoxantrone in multiple sclerosis: serial MRI evaluation at one year. Can $\mathcal{F}$ Neurol Sci 1994;21:266-70.

22 De Castro S, Domenico C, Millefiorini E, Funaro S, Gasperini C, Morino S, et al. Noninvasive assessment of mitoxantrone cardiotoxicity in relapsing remitting multiple sclerosis. F Clin Pharmacol 1995;35:627-32.

23 Confavreux C, Compston DAS, Hommes OR, McDonald WI, Thompson AJ. Edmus, a European database for multiple sclerosis. $f$ Neurol Neurosurg Psychiatry 1992; 55:671-6.

24 Miller DH, Barkhof F, Berry I, Kappos L, Scotti S, 
Thompson AJ. Magnetic resonance imaging in monitoring the treatment of multiple sclerosis: concerted action guidelines. $\mathcal{F}$ Neurol Neurosurg Psychiatry 1991;54 683-8.

25 Miller DH, Albert PS, Barkoff F, Francis G, Frank JA Hodgkinson $\mathrm{S}$, et al. Guidelines for the use of magnetic resonance techniques in monitoring the treatment of multiple sclerosis. Ann Neurol 1996;39:6-16.

26 McFarland HF, Frank JA, Albert PS, Smith ME, Martin $\mathbf{R}$, Harris JO, et al. Using gadolinium-enhanced magnetic resonance imaging lesions to monitor disease activity in multiple sclerosis. Ann Neurol 1992;32:758-66.

27 Stone LA, Frank JA, Albert PS, Bash C, Smith ME, Maloni $H$ McFarland $H F$. The effect of interferon-beta Maloni $\mathrm{H}$, McFarland HF. The effect of interferon-beta on blood-brain barrier distuptions demof trast-enhanced magnetic resonance imaging in relapsing-

28 Moreau T, Thorpe J, Miller DH, Moseley IF, Hale G Waldmann $\mathrm{H}$, et al. Preliminary evidence from magnetic resonance imaging for reduction in disease activity after lymphocyte depletion in multiple sclerosis. Lancet 1994; 344:298-301.

29 Miller DH, Barkhof F, Nauta JJP. Gadolinium enhancement increases the sensitivity of MRI in detecting disease activity in multiple sclerosis. Brain 1993;116:1077-94.

30 Miller DH, Thompson AJ, Morissey SP, MacManus DG Moore SG, Kendall BE. High dose steroids in acute relapses of multiple sclerosis: MRI evidence for a possible mechanism of therapeutic effect. $\mathcal{F}$ Neurol Neurosurg Psychiatry 1992;55:450-3.

31 Crossley RJ. Clinical safety and tolerance of mitoxantrone. Sem Oncol 1984;11(suppl. 1):54-9.

32 Posner LE, Dukart G, Goldberg J, Bernstein T, Cartwright $\mathrm{K}$ Mitoxantrone: an overview of safety and toxicity. Investigational New Drugs 1985;3:123-32.

33 Stone LA, Smith ME, Albert PS, Bash CN, Maloni $\mathrm{H}$ Frank JA, McFarland HF. Blood-brain barrier disruption on contrast-enhanced MRI in patients with mild relapsing-remitting multiple sclerosis. Neurology 1995;45. 1122-6. 